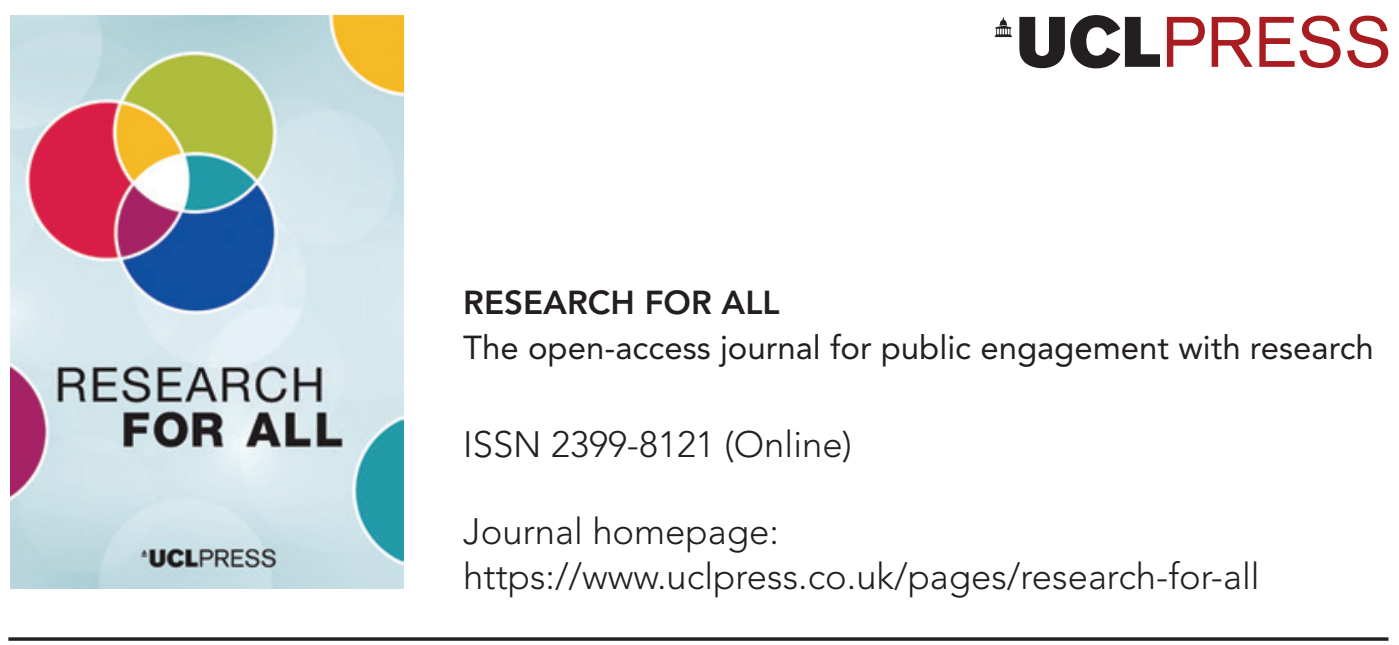

\title{
Editorial: Achieving and demonstrating innovation and new learning in public engagement
}

\author{
Sandy Oliver (iD and Sophie Duncan (iD
}

\section{How to cite this article}

Oliver, S. and Duncan, S. (2021) 'Editorial: Achieving and demonstrating innovation and new learning in public engagement'. Research for All, 5 (1), 1-4.

https://doi.org/10.14324/RFA.05.1.01

Publication date: 16 February 2021

\section{Copyright}

(C) 2021 Oliver and Duncan. This is an open-access article distributed under the terms of the Creative Commons Attribution Licence (CC BY) 4.0 https://creativecommons.org/licenses/ by/4.0/, which permits unrestricted use, distribution and reproduction in any medium, provided the original authors and source are credited.

\section{Open access}

Research for All is a peer-reviewed open-access journal. 


\title{
Editorial: Achieving and demonstrating innovation and new learning in public engagement
}

\author{
Sandy Oliver* - UCL Institute of Education, UK \\ Sophie Duncan* - National Co-ordinating Centre for Public Engagement, UK
}

Research for All has been publishing research and reflections about public engagement with research for four years. The aim is for each contribution to the journal to offer something new, so that knowledge about public engagement is advanced with each issue. This aim raises questions including: How does new learning arise? How can innovation in thinking about, or doing, engagement be demonstrated?

\section{Learning from researching engagement}

Understanding how academics recognize innovation in qualitative research methods has lessons for innovation in public engagement. A review of studies claiming innovation for qualitative methods found that innovation rarely offers wholly new methodologies or designs; rather, innovation was more often adaptations of existing methods, or the transfer and adaptation of methods from other disciplines (Wiles et al., 2011). Similarly, when focusing on the methods practised for public engagement, we cannot expect to often find completely new ways of doing engagement, getting completely new learning from it, or thinking about methods in completely new ways. Instead, innovation and learning are more likely to arise incrementally from a range of strategies including: comparing different methods so as to learn from the big picture (as Wiles et al. (2011) did in their review), or (as they found) from combining established methods in new ways, or applying established methods to a new setting.

Articles in this issue illustrate each of these three strategies. The first strategy is typical of landscape articles that analyse the thinking and activity around an aspect of engaged research. Archer et al. do this in their landscape article that compares different methods for engaging young people in schools with science, technology, engineering and mathematics (STEM): the one-off events, short series of events, and deeper programmes of engagement. They found that young people's aspirations for STEM are less influenced by isolated one-off or short-term interventions, than by sustained programmes involving multiple interactions with the young people and those who influence them.

The second strategy to achieving new knowledge is illustrated by this issue's special feature of five linked articles about an academic mentoring programme for small and medium-sized enterprises (SMEs). These articles reflect on the challenges and achievements of combining what SMEs know with what academics know. Clark-Wilson et al. reflect on the processes and outcomes of the programme as SMEs and academics combine their specialist knowledge of technology, R\&D and social research to enhance innovative products. In addition to the learning that came from evaluating educational 
technology (edtech) products, these articles offer learning about public engagement by reflecting: on direct experiences of working with the different commercial, learning or academic groups that develop, use or evaluate edtech (Luckin); on the mentoring relationship at the heart of the programme (De Ossorno Garcia and Doyle); and on the additional learning that comes from analysing $R \& D$ data alongside academic social science (Morrison et al.; Rogers and Weatherby).

Academic authors typically demonstrate their new learning by referring to what was known before, then claiming to have built on that prior knowledge or filled a gap in that knowledge. They conventionally cite other authors who have published in academic texts before to present what was already known. This format is typical of research articles that develop or test our theoretical understanding of public engagement, or case studies illustrating how theoretical understanding informs practice and how practice develops our theoretical understanding. For instance, Freire's theory of critical pedagogy underpinned Antaki's innovative work with schoolchildren in Mumbai.

But for Research for All, this is only part of the picture, because academic knowledge is only part of the picture. There is also practice knowledge and communities' knowledge heritage.

\section{Learning from practising engagement}

Considerable understanding of public engagement originates not in academic journals, but in the content or discourse of practices. These may be found, more or less formalized, in codes of conduct or established training programmes, or large funded programmes of engaged research. In this issue, the innovation of a school science club (Blaxland et al.) was set against the status quo of the national science curriculum and the pooled experience of teachers who recognized a disconnect between the curriculum and current classroom teaching practices. Teachers saw the success of the engagement coming largely from the lead partner's enthusiasm and effective communication with schools and the joint planning. Case studies such as this are vivid accounts of practice, where the learning about public engagement comes from reflection on the processes of engagement, and whether or how this learning affected those involved, the research and wider society.

Antaki combined two academic disciplines rooted in practice, pedagogy and design, when working with children in a Mumbai school to improve their local environment. While the participative pedagogy helps children 'develop their political identity, and foster their ability to communicate ideas ... Design allows children to develop empathy, think critically and learn how to learn' (Antaki: 104). Both bode well for the children's future engagement with research.

Learning by doing is readily apparent in Farrar's use of participatory action research to achieve research impact through a film festival. By actively engaging audiences in the research, she developed a community of practice, advancing knowledge of, and participation in, extreme sports.

Learning from practice is integral to training programmes that offer researchers, supported by public engagement professionals and others, a safe space to try out engagement and learn from this experience. De Clippele et al.'s art-science collaboration of marine scientists and creative professionals in a communication training programme led to 'creative outputs with the potential to be more influential than a scientific paper' directly affecting the skills, practices and understandings of those involved (135). 
All these examples illustrate people working together and generating lessons for themselves and wider sharing.

\section{Learning from communities' heritage}

Lastly, two articles in this issue explored ideas rooted in heritage. Chubb et al. take the concept of 'edge walking' - comfortably belonging in two or more worlds that differ culturally, ethnically or spiritually - from its origin in psychology and apply it to learn more from and about a community-university research partnership in Kenya. Enacting edge walking opened opportunities to deepen meaningful partnerships.

Also in Africa, Stewart applies the philosophy of ubuntu, which emphasizes interrelationships and dependencies above individualism to analyse evidenceinformed decision-making. The ubuntu lens shines a light on the continent's strong connections between research and policy institutions. Stewart captures a deeply rooted cultural understanding from across Africa in her application of ubuntu to decolonize the field of evidence for decision-making. In doing so, she applies this philosophy of connectedness to analyse the aspiration of connectedness for research and policy. Community knowledge which may be more diffuse and difficult to capture may be apparent in mass media or social media; in civil society organizations' websites or publications; in popular literature; and in knowledge heritage or traditions that are alive in, for instance, songs, proverbs and crafts.

\section{New to whom?}

One of the key challenges of editing Research for All is supporting contributors to decide if and how their work is offering new learning. We often receive interesting papers where the learning offered is new to the authors, but perhaps already articulated elsewhere, in practice communities who do not codify their knowledge in academic journals, or in other disciplines of research that do.

It is a challenge too for us as editors to assess new learning. Our team of associate editors help ensure that we cover the breadth and depth of engagement with research practice, but collectively there will still be gaps in our knowledge base. Our peer reviewers are drawn from specific academic and practice communities to ensure that we are offering perspectives relevant to the article.

We hope that this editorial offers some ideas about recognizing what is new about your work. Is it pioneering practice, or existing practice seen from new standpoints, or practice well versed in one context being applied somewhere new? As we continue our work to progress understanding and practice of public engagement with research, we are learning together how to do this through the pages of a journal. We have learned a lot, and look forward to continuing to work together to inspire new ideas, new approaches and new learning. And if sometimes you come across articles where the learning is not new to you, be generous, as it may be new to others.

\section{Articles in this issue}

Antaki, N. (2021) 'A learning architecture: Developing a collective design pedagogy in Mumbai with Muktangan School children and the Mariamma Nagar community'. Research for All, 5 (1), 101-17. https://doi.org/10.14324/RFA.05.1.09.

Archer, M., DeWitt, J., Davenport, C., Keenan, O., Coghill, L., Christodoulou, A., Durbin, S., Campbell, H. and Hou, L. (2021) 'Going beyond the one-off: How can STEM engagement programmes with young people have real lasting impact?'. Research for All, 5 (1), $67-85$. https://doi.org/10.14324/RFA.05.1.07. 
Blaxland, J., Thomas, R. and Baillie, L. (2021) 'Development of the School Science Club at Cardiff University'. Research for All, 5 (1), 86-100. https://doi.org/10.14324/RFA.05.1.08.

Chubb, L.A., Fouché, C.B. and Sadeh Kengah, K. (2021) 'Co-researching complexities: Learning strategies for edge walking in community-university research partnerships'. Research for All, 5 (1), 157-73. https://doi.org/10.14324/RFA.05.1.12.

Clark-Wilson, A., Moeini, A., Anand, K., Blake, C., Cukurova, M., De Ossorno Garcia, S., Issroff, K., Luckin, R., Olatunj, T., Outhwaite, L. and Weatherby, K. (2021) 'Supporting small and mediumsized enterprises in the educational technology sector to become more research-minded: Introduction to a small collection'. Research for All, 5 (1), 5-15. https://doi.org/10.14324/ RFA.05.1.02.

De Clippele, L., Michelotti, M., Findlay, C.R., Cartwright, A., Fang, Q., Wheatley, C., Sladen, A., Scott-Somme, K., Harding, H.R., Jackson, J., Hepburn, L.E., Giannotti, J., Carroll, G., Heidtke, N., Worrall, A.M. and De Meyer, K. (2021) 'The Future of Our Seas: Marine scientists and creative professionals collaborate for science communication'. Research for All, 5 (1), 134-56. https://doi.org/10.14324/RFA.05.1.11.

De Ossorno Garcia, S. and Doyle, L. (2021) 'The mentoring relation as an interpersonal process in EDUCATE: A qualitative case study of mentor-mentee perspectives'. Research for All, 5 (1), 19-35. https://doi.org/10.14324/RFA.05.1.04.

Farrar, R. (2021) 'Creating impact through participatory action research: A film festival framework case study'. Research for All, 5 (1), 118-33. https://doi.org/10.14324/RFA.05.1.10.

Luckin, R. (2021) 'What inspired my thinking to create UCL EDUCATE?'. Research for All, 5 (1), 16-18. https://doi.org/10.14324/RFA.05.1.03.

Morrison, M., Blake, C., Embleton-Smith, F., Gosiewski, J. and Zvesper, J. (2021) 'Pre-emptive intervention and its effect on student attainment and retention'. Research for All, 5 (1), 36-51. https://doi.org/10.14324/RFA.05.1.05.

Rogers, E. and Weatherby, K. (2021) 'Developing Little Bridge as an evidence-informed English language learning platform for 6-12 year olds'. Research for All, 5 (1), 52-66. https://doi.org/10.14324/RFA.05.1.06.

Stewart, R. (2021) 'Turning "evidence for development" on its head: A view from Africa'. Research for All, 5 (1), 174-87. https://doi.org/10.14324/RFA.05.1.13.

\section{Acknowledgements}

Research for All is a collaborative project that relies on a range of associate editors with experience of engaged research in a variety of contexts. The associate editors who advised us on the content for this issue of the journal are:

- Hilary Jackson - University College London, UK

- Janet Jull - Bruyère Research Institute and University of Ottawa, Canada

- Norbert Steinhaus - Living Knowledge: The International Science Shop Network, Germany

- Crystal Tremblay - University of Victoria, Canada.

We extend our thanks to them and to all the expert reviewers - two for each contribution who helped us guide authors towards their final drafts.

\section{Reference}

Wiles, R., Crow, G. and Pain, H. (2011) 'Innovation in qualitative research methods: A narrative review'. Qualitative Research, 11 (5), 587-604. https://doi.org/10.1177/1468794111413227. 